\title{
INFLUENCE OF PRESSURE OSCILLATIONS IN COMMON RAIL INJECTOR ON FUEL INJECTION RATE
}

\author{
Mikhail G. Shatrov1, Andrey U. Dunin ${ }^{1}$, Pavel V. Dushkin', \\ Andrey L. Yakovenko ${ }^{1}$, Leonid N. Golubkov ${ }^{2}$, Vladimir V. Sinyavski ${ }^{2}$ \\ ${ }^{1}$ Ishlinsky Institute for Problems in Mechanics RAS, Moscow, Russia \\ ${ }^{2}$ Energo-Ecological Faculty, Moscow Automobile and Road Construction \\ State Technical University (MADI), Moscow, Russia
}

\begin{abstract}
Fuel injection causes considerable oscillations of fuel pressure at the injector inlet. One of the reasons is hydraulic impact when the needle valve closes. For multiple injections, the previous injections affect the following. As both the fuel pressure in rail pac and the injection rate grow, the oscillations increase. The pressure oscillation range at the common rail injector inlet at $p_{a c}=1500$ bar is up to 350 bar, and at the rail pressure $p_{a c}=500 \mathrm{bar}$, the amplitude decreases to 80 bar. Physical properties of the fuel are also important. As the viscosity of the fuel increases, its hydraulic friction grows which results in a rapid damping of pressure oscillations. The data for an injector operating on sunflower oil is presented. As compared with diesel fuel, the oscillations range decreases from 400 to 250 bar at the same operating mode. The influence of the interval between the impulses of a double injection on the injection rate of the second fuel portion was investigated. Superposition of two waves during multiple injections may result in amplification and damping of the oscillations. Simulation was performed to estimate the influence of fuel type and time interval $\Delta \tau$ between control impulses of a double injection on the injection quantity of the second portion at pressures of 2000-3000 bar. When the rail pressure $p_{a c}$ grows, the oscillations and their impact on the injection process increase. For diesel fuel at pressure of $p_{a c}=2000$ bar, the variation in injection rates of the second portion is $2.36-4.62 \mathrm{mg}$, and at $p_{a c}=3000 \mathrm{bar}-1.58-6.63 \mathrm{mg}$.
\end{abstract}

Key Words: Common Rail Fuel System, Common Rail Injector, Hydrodynamic Effects, Pressure Oscillations, Fuel Injection Rate

Received June 11, 2020 / Accepted October 30, 2020 Corresponding author: Vladimir Sinyavski

Moscow Automobile and Road Construction State Technical University, 64, Leningradsky prospect, Moscow, 125319, Russia

E-mail: sinvlad@mail.ru 


\section{INTRODUCTION}

The development of engines with perspective energetic and ecological parameters demands the development of new versions of the fuel supply system for different models of diesel engines. In this connection, important tasks are ensuring injection pressure up to 2000 bar and higher as was investigated by Pflaum [1], Shatrov [2], Yu [3], Bosch company [4], as well as the injection rate front shape control and organization of fuel distribution in the combustion chamber which was studied by Shatrov [5], Kamaltdinov [6], Iakovenko [7], Wuethrich [8]. It was demonstrated by Wloka [9], Grekhov [10], Zhao [11], VeraTudela [12] that the desired fuel injection law at any operation mode of the engine is formed by variation of the control impulse duration and pressure in the common rail. It also depends on the wave phenomenon originating in the high-pressure line and having a considerable impact on the fuel injection process in the case of a multistage injection.

The pressure growth in case of multiple injections makes the fuel injection process more complicated. Baratta [13], Beirer [14], Catania [15] and experiments carried out in MADI demonstrated that the pressure oscillations at the injector inlet become crucial.

Beirer [14] investigated the influence of hydrodynamic effects in the fuel line on pressure oscillations in the Common Rail Injector (CRI).

The oscillations grow as the channel length increases and the diameter decreases. But the fuel line also influences their frequency. For example, if the fuel line length increases, the frequency decreases. This is explained by the fact that the pressure wave travel time in a long channel is higher. Oscillation process increases with the growth of the fuel pressure in the common rail and control impulse duration.

It was demonstrated that depending on the interval between two portions of double injection, the injection rate could vary considerably. The wave process that originates when one CRI injects fuel has an impact on fuel injection process of the injectors belonging to the other diesel engine cylinders.

Iakovenko [7] made a conclusion about the reasons of the pressure oscillations: pressure oscillations are triggered by the so called "water-hammer" effect induced by the nozzle closure at the end of each injection. When the fuel is flowing via the nozzle holes during injection process, its kinetic energy grows which is transformed into the energy of the pressure waves when the needle valve closes and the flow stops abruptly.

Beirer [14] found in his research that the fuel pressure oscillations cannot be the reason of the resonance of the mechanical parts of the fuel system because their natural oscillation frequency is considerably lower than the frequency of the wave process in the hydraulic circuit. However, the authors demonstrated the possibility of the origination of the hydraulic resonance which takes place when the needle closes as soon as the compression wave reaches the nozzle due to the reflection of the injection-induced depression wave in the rail.

When the injector needle valve closes on its seat, the hydraulic impact takes place. The pressure wave and the direct pressure wave (compression wave) which originate as a consequence appear to be in the same phase which causes intensive pressure oscillations in the delivery line. It is important to take into consideration this effect in the case of multiple injections and seek to avoid it.

The analyses of the injector design influence on the wave process are of a high interest. For example, here it is demonstrated that in a nozzle having holes on the locking cone, the hydraulic impact when the injector is closing is not so strong as in the case of a nozzle having holes in the sack volume. 
The results described need to be supplemented by data on the ways of prevention of oscillation effects and the influence of fuel properties on them. The present paper presents the results of solving these scientific tasks.

\section{EXPERIMENTAL SETUP}

The experimental setup (Fig. 1) has a modular design making possible its adaptation for current research tasks and various designs of fuel systems. This setup consists of the following parts:

- asynchronous electric motor $3(7.5 \mathrm{~kW}, 3000 \mathrm{rpm})$ with a thyristor transducer 12 enabling a smooth control of rotational speed;

- low-pressure fuel line which includes a low-pressure fuel pump 16, $12 \mathrm{~V}$ and $24 \mathrm{~V}$ electric power supply units $8-9$, fine-mesh fuel filter 15 .

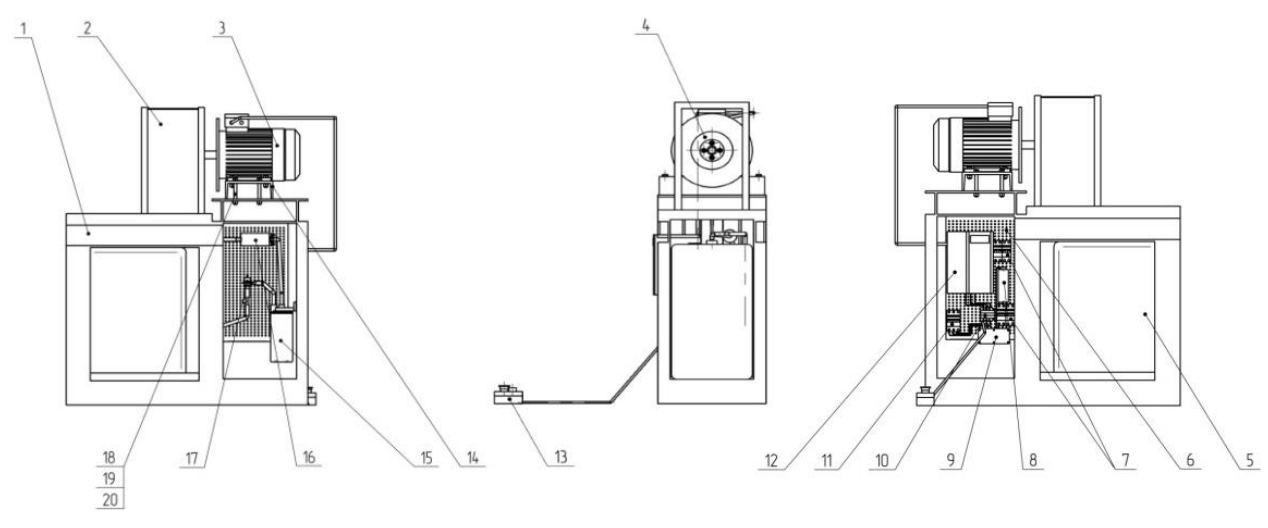

Fig. 1 Experimental setup: 1 - frame; 2 - protective casing; 3 - asynchronous electric motor; 4 - coupling; 5 - fuel tank; 6 - mounting plate; 7, 11 - fuses; 8, 9 - electric power supply units; 10 - magnetic contactor; 12 - thyristor transducer; 13 - emergency stop switch; 14 - electric motor mounting; 15 - fine fuel filter; 16 - low-pressure fuel pump; 17 - fuel pressure regulator; 19, 20 - elements mounting the electric motor on the frame

The fuel system (Fig. 2) of the experimental setup includes: high-pressure pump 1, fuel accumulator 2 with pressure sensor 16 , fuel line 5 (length $l_{\mathrm{fl}}=1000 \mathrm{~mm}$, channel diameter $d_{\mathrm{fl}}=2.2 \mathrm{~mm}$ ) and electro-hydraulic injector 3 . The experimental stand is equipped with a control system developed in MADI. The difference is that the newly developed control system ensures the formation of any shape of electric control pulse. This feature is fundamentally important in the study of pressure oscillations in the diesel fuel system. 


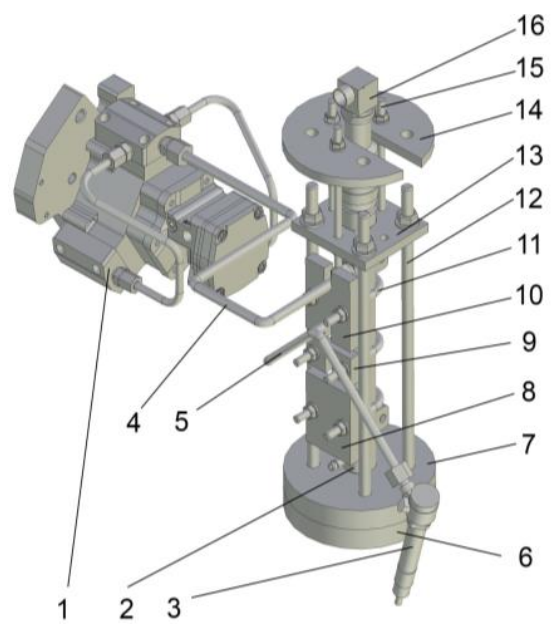

Fig. 2 Fuel system of the experimental setup: 1 - high-pressure fuel pump; 2 - fuel accumulator; 3 - electro-hydraulic injector; 4, 5 - high-pressure fuel lines; 6, 7 - fuel accumulator mounting plates; 8, 9, 10, 14 - clamping plates; 11 - fixings; 12 - fuel accumulator fixing pin; 13 - pressure sensor mounting plates; 15 - pressure sensor fixing pin; 16 - pressure sensor

Electromagnetic drive of the control valve is used in two electro-hydraulic injectors (Fig. 3). The second electro-hydraulic injector (fuel injector nozzle hole diameter $d_{\mathrm{c}}=0.09$ $\mathrm{mm}$, number of holes $i_{\mathrm{c}}=8$, Fig. 3b) differs from the first injector (fuel injector $d_{\mathrm{c}}=0.12$ $\mathrm{mm}, i_{\mathrm{c}}=7$, Fig. $3 \mathrm{a}$ ) with the presence of a fuel accumulator 6 integrated into the body 3 and with the design of the control valve 2 .
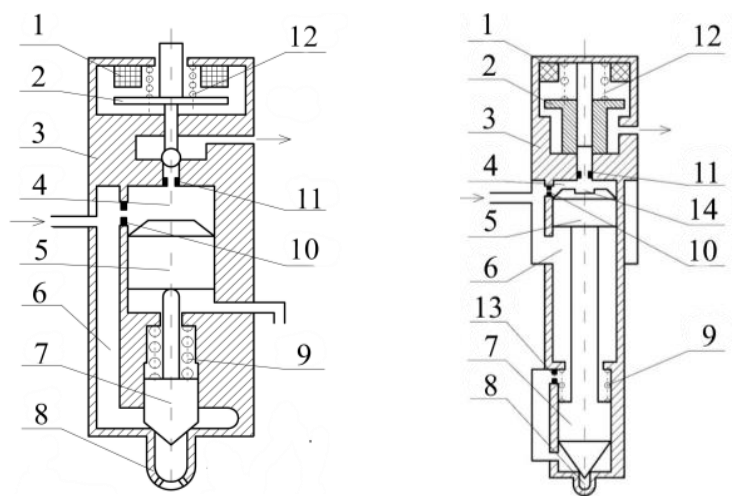

Fig. 3 Layouts of the injectors: a - injector No1, b - injector No2, 1 - solenoid, 2 - control valve, 3 - CRI body, 4 - control chamber, 5 - multiplier (for version b, elements 5 and 7 are one piece); 6 (a) - channel supplying fuel to the injector nozzle; 6 (b) - fuel accumulator; 7 - injector nozzle needle; 8 - injector nozzle; 9 - needle valve spring; 10 - inlet throttle; 11 - outlet throttle; 12 - valve spring; 13 - additional throttle; 14 - channel 
The experimental setup is complemented by two piezoelectric sensors T6000, manufactured in Russia. The first sensor (No 4636 having sensibility $2.1 \mathrm{pC} / \mathrm{bar}$ and pressure measuring range $0 \ldots 6000 \mathrm{bar}$ ) is mounted at the inlet of the CRI and registers the pressure oscillations when the fuel is injected. The second sensor (No 4588 having sensibility 2.2 $\mathrm{pC} / \mathrm{bar}$ and pressure measuring range $0 \ldots 6000$ bar) is mounted in the chamber and registers the instants of the fuel injection start and its end.

The magnitude of fuel injection rate $Q$ is measured by the gravimetric method. When determining $Q$ of each point, the measurement is carried out twice, which allows us determine the random measurement error of this magnitude $(\Delta Q)$. The instrument error of high-precision scales is neglected since its value is substantially less than the random measurement error. Each measurement provides $\Delta Q$ not less than $\pm 5.0 \%$, which is achieved by selecting a sufficient number of consequent cycles.

The measurement errors of the inlet pressure in the injector and fuel accumulator are determined by the accuracy of measuring instruments. Therefore, calibration of pressure sensors T6000 and DMP304 (manufactured in Germany, pressure measuring range 0...4000 bar) is previously conducted.

The experiment was carried out in two stages: the first stage - the injector operates in a single injection mode; the second stage - the injector operates in a multiple injection mode.

\section{RESULTS AND DISCUSSION}

The influence of some factors upon pressure oscillations at the CRI inlet was investigated: fuel pressure $p_{\text {ac }}$, control impulse duration $\tau_{\text {imp }}$, type of fuel used. With this, two different injectors having principally different design were studied in the experiment.

Two types of the fuels were used: a fossil-origin diesel fuel and renewable sunflower oil (Table 1).

Table 1 Properties of the fuels used

\begin{tabular}{lcc}
\hline Properties & Diesel fuel & Sunflower oil \\
\hline Density $\left(\mathrm{t}=20^{\circ} \mathrm{C}\right), \mathrm{kg} / \mathrm{m}^{3}$ & 820 & 923 \\
Kinematic viscosity $\left(\mathrm{t}=20^{\circ} \mathrm{C}\right), \mathrm{mm}^{2} / \mathrm{s}$ & 3.0 & 65.2 \\
Cetane number & 45 & 33 \\
Low calorific value, $\mathrm{MJ} / \mathrm{kg}$ & 42.5 & 37.0 \\
\hline
\end{tabular}

Fuel injection causes considerable oscillations of fuel pressure at the inlet of the injector. One of the reasons is hydraulic impact which originates when the injector nozzle needle closes. In this case, in injector No1 with pressure $p_{\mathrm{ac}}=1000$ bar and control impulse duration $\tau_{\text {imp }}=0.6 \mathrm{~ms}$ (which corresponds to fuel injection rate $Q=16.5 \mathrm{mg}$ ), the injection causes the origination of pressure oscillations which have the amplitude up to $250 \mathrm{bar}$ (Fig. 4). Evidently these oscillations have influence upon the fuel supply process in the case of multiple injections: the previous injections would influence the following ones. 


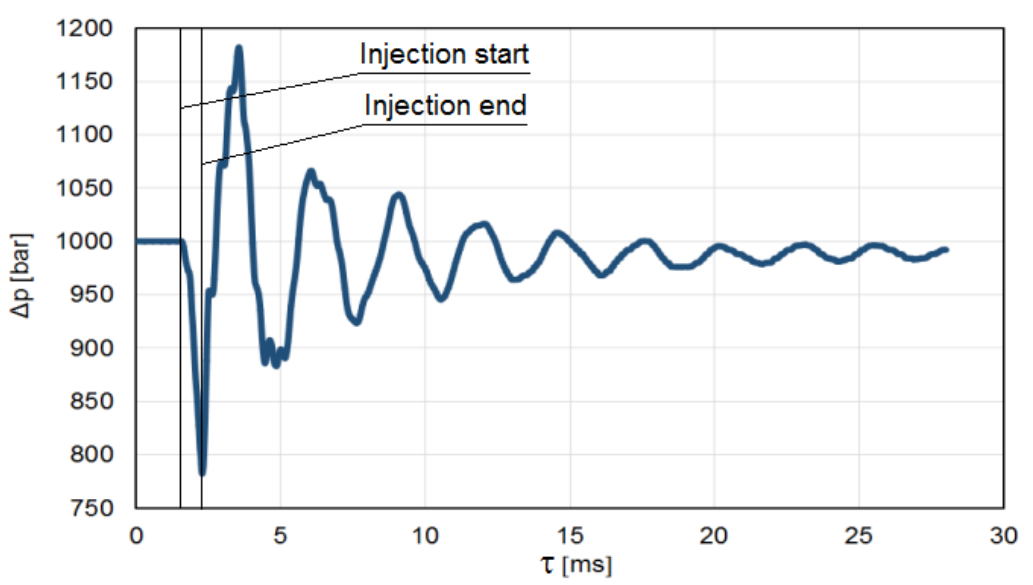

Fig. 4 Pressure at the inlet of the CRI No 1 ( $p_{\text {ac }}=1000$ bar, $\tau_{\text {imp }}=0.6 \mathrm{~ms}, Q=16.5 \mathrm{mg}$ )

As the fuel pressure and injection rate grow, the oscillation process increases. Fig. 5 shows the comparison of data registered at three pressures in the fuel accumulator and constant control impulse duration $\tau_{\text {imp }}=0.6 \mathrm{~ms}$. A single injection is used in this case.

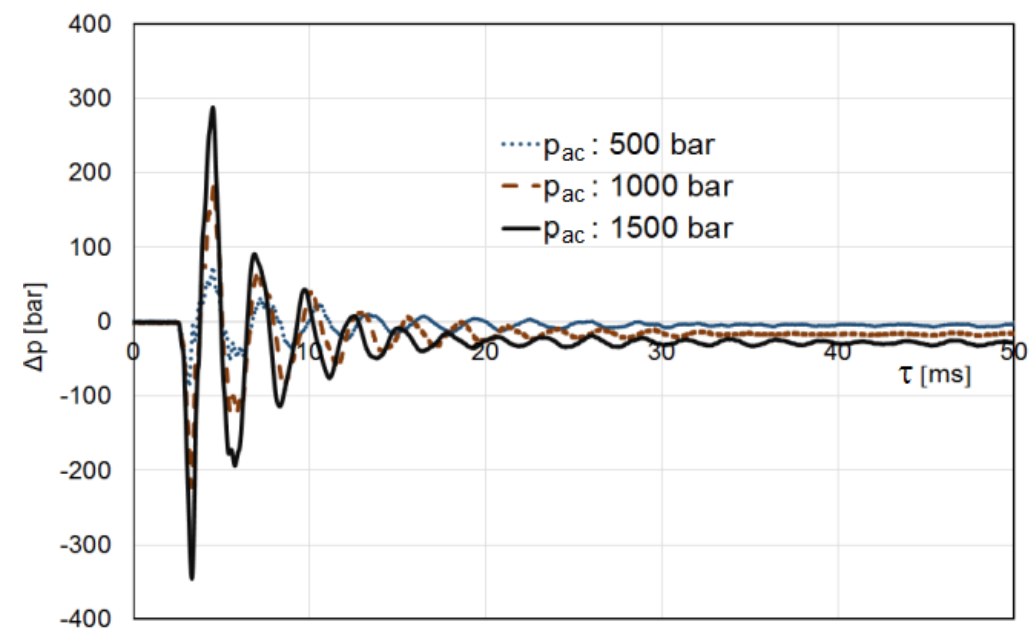

Fig. 5 Fuel pressure oscillations at the entry of the CRI No1 at various pressures $\left(\tau_{\mathrm{imp}}=0.6 \mathrm{~ms}\right): Q=9.1 \mathrm{mg}\left(p_{\mathrm{ac}}=500 \mathrm{bar}\right) ; Q=16.5 \mathrm{mg}$ ( $\left.p_{\mathrm{ac}}=1000 \mathrm{bar}\right) ; Q=38.3 \mathrm{mg}$ ( $p_{\text {ac }}=1500 \mathrm{bar}$ )

The pressure oscillation range at the CRI inlet is up to 350 bar at $p_{\mathrm{ac}}=1500 \mathrm{bar}$, and at $p_{\text {ac }}=500 \mathrm{bar}$, the amplitude decreases to 80 bar.

Fig. 6 shows both the comparison and the variation of the first control impulse duration at constant pressure in the fuel accumulator $p_{\mathrm{ac}}=1000 \mathrm{bar}$. On the basis of this ne 
can conclude that as the first portion of the fuel injected decreases, the fuel pressure oscillations range also decreases.

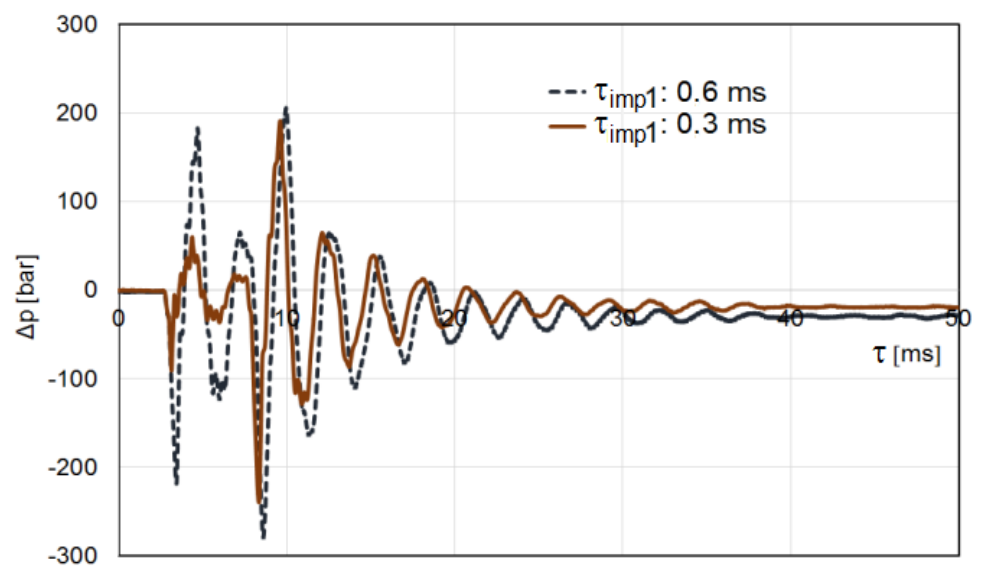

Fig. 6 Fuel pressure oscillations at the entry of the CRI No1 at various duration of the first injection ( $\left.p_{\mathrm{ac}}=1000 \mathrm{bar}\right): Q=2.2 \mathrm{mg}\left(\tau_{\mathrm{imp}}=0.3 \mathrm{~ms}\right) ; Q=16.5 \mathrm{mg}\left(\tau_{\mathrm{imp}}=0.6 \mathrm{~ms}\right)$

Fig. 7 shows the experimental data for modified injector No2 at the operation mode $p_{\mathrm{ac}}=1000 \mathrm{bar}$ and $\tau_{\mathrm{imp}}=0.6 \mathrm{~ms}$. Compared with the No1 version of the CRI (Fig. 5), the pressure oscillations are considerably lower. The pressure oscillations range for the version No1 is 400 bar, and for the version No2 - 120 bar, that is, 3.3 times lower.

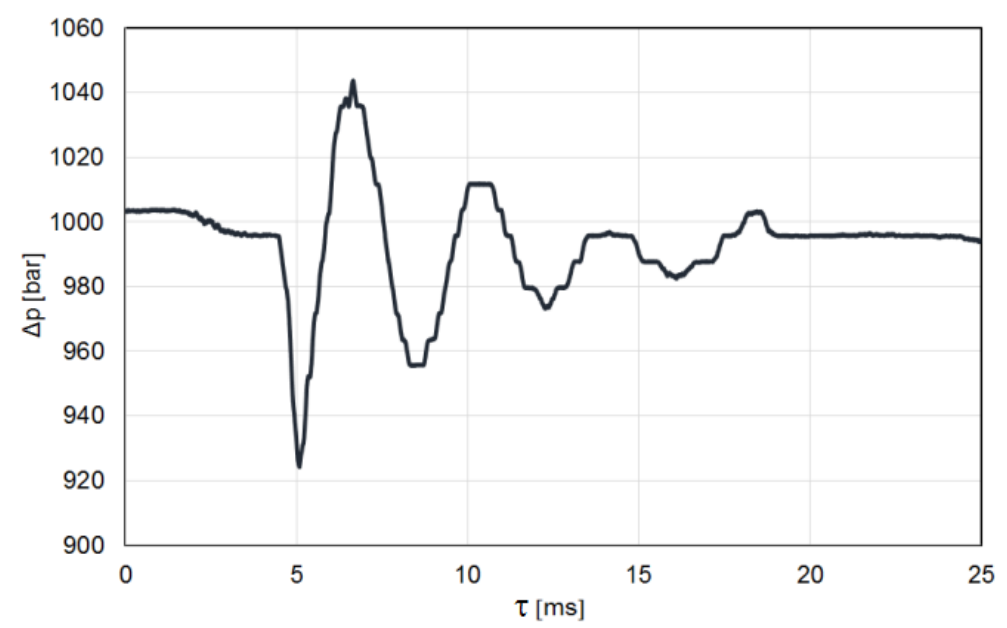

Fig. 7 Pressure at the inlet of the CRI No2 ( $\left.p_{\mathrm{ac}}=1000 \mathrm{bar}, \tau_{\mathrm{imp}}=0.6 \mathrm{~ms}, Q=24.0 \mathrm{mg}\right)$

Hence, the reduced internal volume of the injector plays a considerable role and may be an efficient measure for lowering the pressure oscillations. 
Injector No2 has a pressure balanced valve in addition to the integrated fuel accumulator. Leonard [16] proved that the balanced valve makes it possible not only to decrease the volume of fuel leaks at high pressure, but also to improve the injector working process in the case of multiple injections.

Physical properties of the used fuel are also important in the fuel injection process. As the fuel viscosity increases, so does the hydraulic friction which contributes to a rapid damping of the oscillations. Fig. 8 shows the data obtained with the use of injector No1 when operating on more viscous sunflower oil. As compared with diesel fuel (Fig. 4), the oscillations range decreases from 400 to 250 bar at the same operating mode.

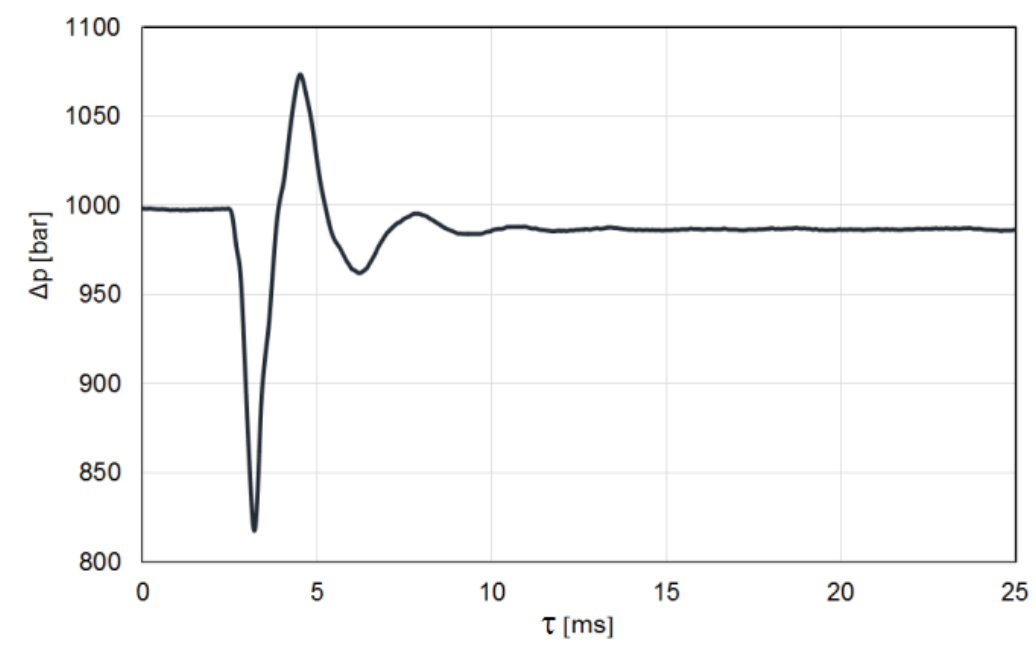

Fig. 8 Pressure at the inlet of the CRI No1 ( $p_{\text {ac }}=1000$ bar, $\left.\tau_{\text {imp }}=0.6 \mathrm{~ms}, Q=15.9 \mathrm{mg}\right)$, operation on sunflower oil

The influence of the interval between the impulses of a double injection on the injection rate value of the second portion was investigated. Injector No1 was used.

The oscillograph trace of a current passing through the electric magnet of injector No1 is shown in Fig. 9. The injector control is carried out in two phases: forcing and holding. For forcing, the voltage of about $50 \mathrm{~V}$ is applied to the electric magnet during $0.3 \mathrm{~ms}$ which promotes a rapid raise of the control valve. The injector needle is kept under control by using pulse-width modulation with duty ratio of $50 \%$.

The injection rate and injection characteristic of the second portion depend on the time at which the second injection is affected related to the first injection. Fig. 10 shows the results of the investigations at constant pressure $p_{\mathrm{ac}}=1000 \mathrm{bar}$ with two injections each having $\tau_{\text {imp }}=0.6 \mathrm{~ms}$ when there is a variable interval $\Delta \tau_{\text {imp }}$ between two portions of the double injection. The vertical line in the picture designates the fuel injection start instant.

Superposition of the waves during operation with the multiple injections may result in both the amplification and the damping of the pressure oscillations process. If the second injection is executed at the rear wave edge (pressure increase) or in the minimal pressure zone - the oscillations damping takes place. If or when the second injection is executed at the front (decreasing) wave edge or in the maximal pressure zone, the oscillations increase. 


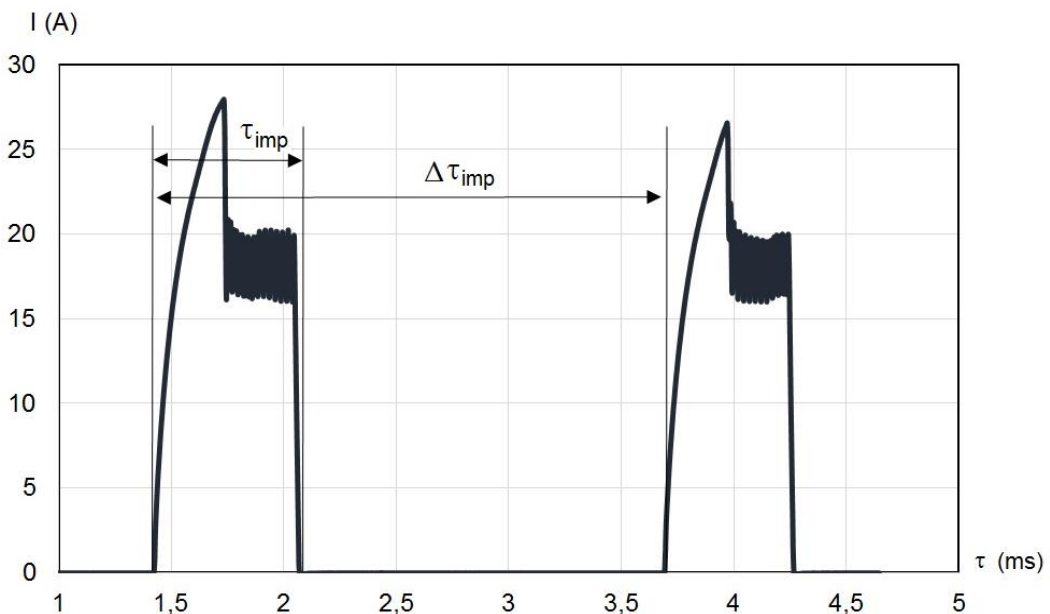

Fig. 9 Oscillograph trace of a current passing through the electric magnet of injector No1 (double injection): $\tau_{\text {imp }}$ - control impulse duration, $\Delta \tau_{\text {imp }}$ - interval between two portions of the double injection

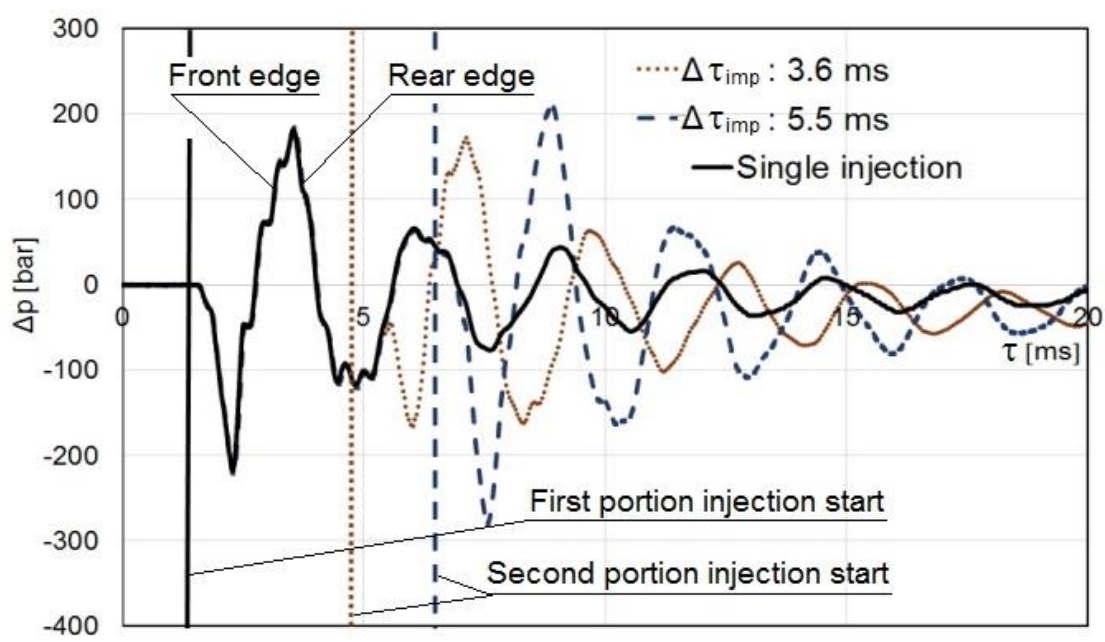

Fig. 10 Pressure oscillations at the inlet of the CRI No1 at various intervals between the double injection $\Delta \tau_{\text {imp }}\left(p_{\text {ac }}=1000\right.$ bar $): Q=17.5 \mathrm{mg}\left(\Delta \tau_{\text {imp }}=3.6 \mathrm{~ms}\right) ; Q=9.5 \mathrm{mg}$ $\left(\Delta \tau_{\mathrm{imp}}=5.5 \mathrm{~ms}\right)$

Fig. 10 shows that at the interval of $\Delta \tau_{\text {imp }}=3.6 \mathrm{~ms}$, after injection of the second portion, the maximal pressure oscillations range is 330 bar. While at the interval of $\Delta \tau_{\text {imp }}=5.5 \mathrm{~ms}$, the maximal oscillation range increases ( 1.45 times) to 480 bar.

Fig. 11 shows the results of estimation of the dependence of injector rate $Q$ of the second injection on the interval between the injections. The first injection value is constant and amounts to $Q_{1}=16.5 \mathrm{mg}$. The difference between the first and the second magnitudes of the injection rate is almost 2 times. 
It should be mentioned that the average value of the second injection rate is considerably lower than that of the first injection rate.

Even if the beginning of the second injection is shifted from the first injection to the interval of $\Delta \tau_{\text {imp }}=50 \mathrm{~ms}$, the value of the second portion is $13.1 \mathrm{mg}$ which is by $3.4 \mathrm{mg}$ lower than the first one, in spite of the fact that the pressure oscillations created by the first injection are damped completely during $50 \mathrm{~ms}$.

The background of the revealed phenomenon has two potential explanations.

First, the pressure in the fuel accumulator decreases after the first injection. The pressure deviation value is not large and according to data presented in Figs. 5 and 6, it amounts to 50 bar (depending on the operation mode).

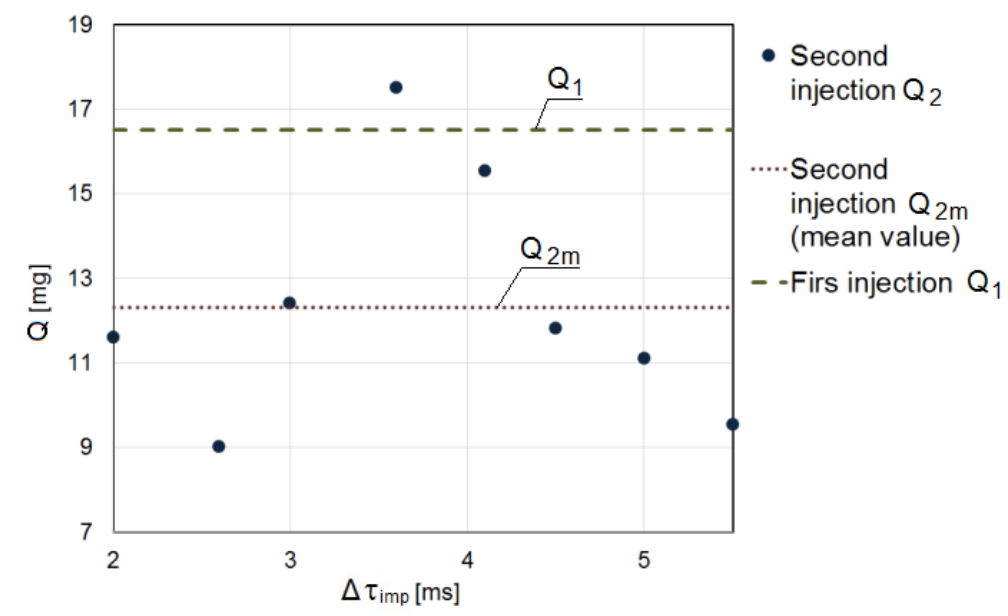

Fig. 11 Fuel injection rate at various intervals between the injections $\Delta \tau_{\text {imp }}$ ( $p_{a c}=1000$ bar, $\tau_{\text {imp }}=0.6 \mathrm{~ms}$ )

The second factor is the voltage slump on the injector power supply condenser. As it follows from oscillograph traces in Fig. 9, the forcing current of the second injection is by 2.5 A lower than the first one which causes longer opening of the injector.

This is the answer why the modern injection systems also make stringer requirements to such parameters as fuel pressure control dynamics and charging of the power supply condenser of the injectors.

Injection characteristic of the second fuel portion also depends on $\Delta \tau_{\text {imp }}$ because the pressure built up in the needle valve volume is interlinked with the pressure at the CRI inlet. For example, if the injection of the second fuel portion starts in the minimal zone of the pressure wave and terminates in the maximal zone of the pressure wave (Fig. 10), the fuel flow velocity through the spray holes will vary with the continuing injection process from low to high value.

Simulation was carried out to estimate the influence of fuel type and time interval $\Delta \tau$ (Fig. 12) between the control impulses of the double injection on the value of the injection quantity of the second fuel portion at pressures $2000 \ldots 3000$ bar. 


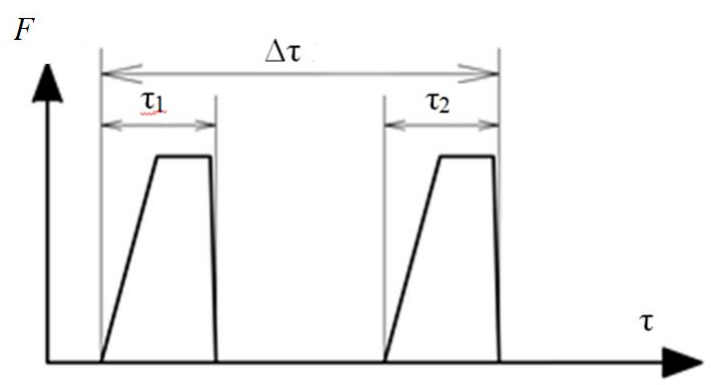

Fig. 12 Control impulses modeled: $F$ - injector electromagnet force, $\Delta \tau$ - time interval between the control impulses, $\tau_{1}-$ the first control impulse duration, $\tau_{2}-$ the second control impulse duration

Simulation was carried out using the software package for modeling fuel system operation developed in MADI.

In this software package, the fuel system is divided into the following elements:

- basic units: injectors, high-pressure fuel pump;

- connecting parts: fuel lines and fuel accumulator.

Each element contains equations integrated into the system and describing:

- the law of conservation of momentum for the mechanical moving parts of the fuel system;

- volume and mass balances for the internal volumes and cavities of the high-pressure line of the fuel system.

The elements are connected with each other by fuel lines, in which wave phenomena takes place. They are modeled taking into account hydraulic friction in the high-pressure line. The systems of equations describing processes in the fuel system elements are the boundary conditions for calculation of the wave phenomena in the high-pressure line.

The fuel flow in the high-pressure line channels is considered isothermal, and the fuel density and sound velocity are constant. The processes occurring in the volumes contained in the injector and the high-pressure fuel pump are considered equilibrium. In the computer model, yielding of the final volumes and fuel lines is not taken into account.

The CRI No2 was selected as a subject of the research because it provides a smaller pressure oscillations range.

Two equal control impulses were modeled $\left(\tau_{1}=\tau_{2}\right)$. We selected such duration of control impulses $\tau$ that the fuel quantity supplied during the first injection was $Q_{1} \approx 3 \ldots 4 \mathrm{mg}$.

Modeling results of the operation of the CRI No2 on diesel fuel for two fuel pressures in the rail of $p_{\mathrm{ac}}=2000$ and 3000 bar are presented in Figs. 13 and 14.

As was demonstrated during experimental tests carried out in MADI (Fig. 11), pressure oscillations at the injector inlet were the reason of variation of the injection rates as a function of $\Delta \tau$. 


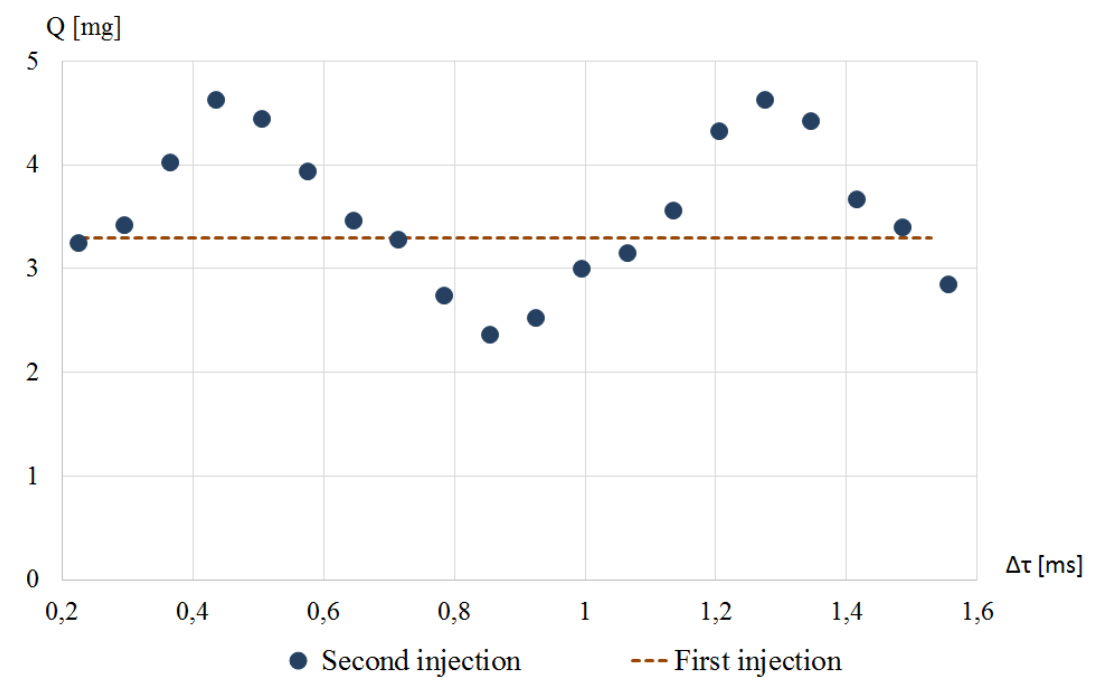

Fig. 13 Fuel injection rate $Q_{2}$ at different intervals between injections $\Delta \tau$ for diesel fuel $\left(Q_{1}=3.3 \mathrm{mg}\right): p_{\mathrm{ac}}=2000 \mathrm{bar}$

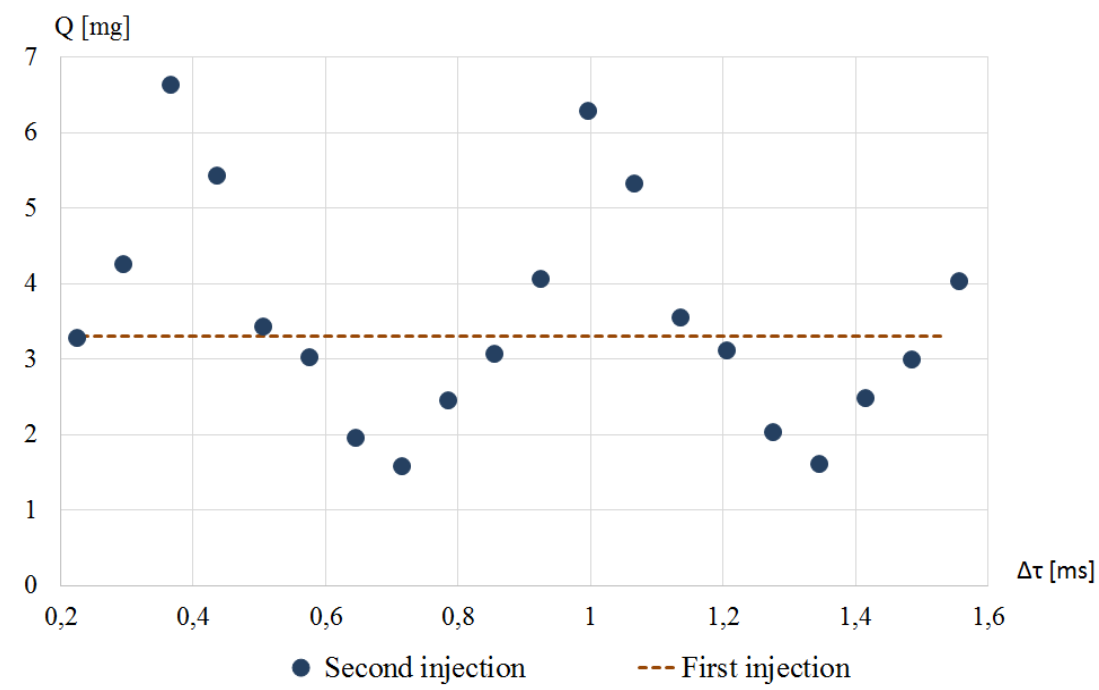

Fig. 14 Fuel injection rate $Q_{2}$ at different intervals between injections $\Delta \tau$ for diesel fuel $\left(Q_{1}=3.3 \mathrm{mg}\right): p_{\mathrm{ac}}=3000 \mathrm{bar}$

When pressure $p_{\text {ac }}$ grows, the oscillation phenomenon and its impact on the working process increase. When operating on diesel fuel at pressure $p_{\mathrm{ac}}=2000 \mathrm{bar}$, the spread in the injection rates of the second portion is $Q_{2}=2.36 \ldots 4.62 \mathrm{mg}$, and at $p_{\mathrm{ac}}=3000 \mathrm{bar}, Q_{2}=$ $1.58 \ldots 6.63 \mathrm{mg}$. 
The results of fuel injection rate $Q_{2}$ variation calculated for a higher density fuel corresponding to the sunflower oil are presented in Figs. 15 and 16.

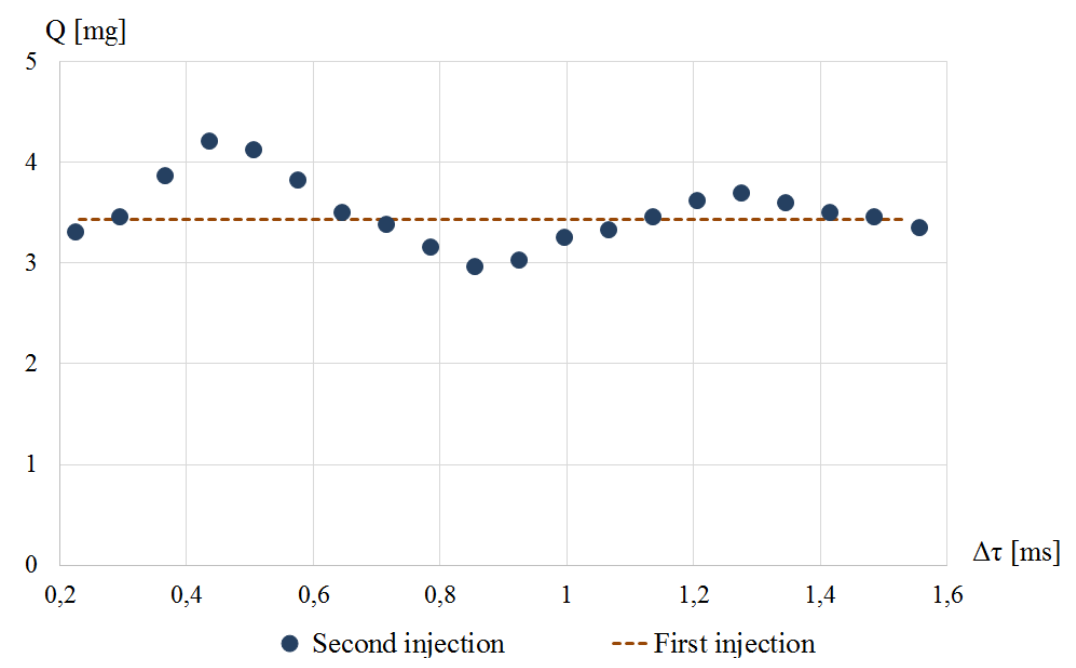

Fig. 15 Fuel injection rate $Q_{2}$ at different intervals between injections $\Delta \tau$ for a higher density fuel $\left(Q_{1}=3.4 \mathrm{mg}\right): p_{\mathrm{ac}}=2000 \mathrm{bar}$

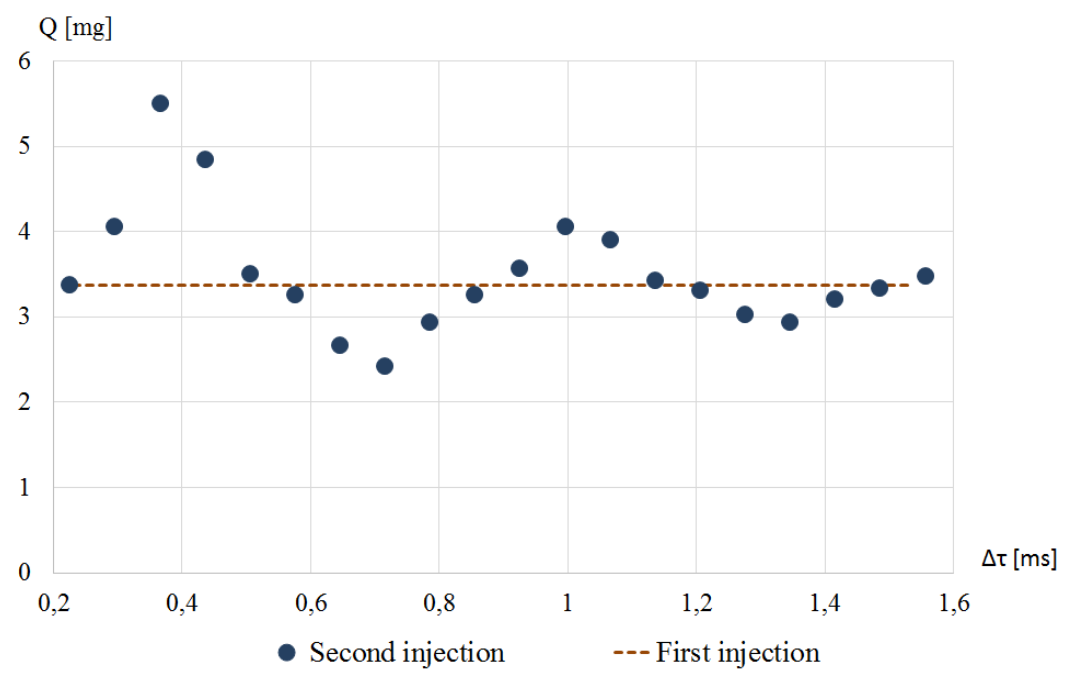

Fig. 16 Fuel injection rate $Q_{2}$ at different intervals between injections $\Delta \tau$ for a higher density fuel $\left(Q_{1}=3.4 \mathrm{mg}\right)$ : $p_{\mathrm{ac}}=3000 \mathrm{bar}$

The main difference between the test results given in Figs. 13, 14 and Figs. 15, 16 is a faster attenuation of the oscillations observed when passing to a more dense fuel. In the case of $p_{\mathrm{ac}}=2000 \mathrm{bar}$, the spread in the injection rates of the second portion is $Q_{2}=$ $2.96 \ldots 4.21 \mathrm{mg}$, and at $p_{\text {ac }}=3000 \mathrm{bar}-Q_{2}=2.42 \ldots 5.50 \mathrm{mg}$. 
It is seen from comparison of calculated data (Fig. 13 ... Fig. 16) that due to a higher hydraulic friction, the range of maximal pressure oscillations is lower. This will have a positive effect on the control accuracy of the second portion of a higher density fuel injected.

The pressure oscillations that are described above should be taken into consideration when applying the injection rate shaping control method developed in MADI in which electric control impulses are used. The method of injection rate shaping is employed in the cases when the control impulse strategy consists of the primary, main and post impulses. Electric impulses are supplied from the electronic control module to the electromagnetic valves of injector No1 and injector No2 (Fig. 3). Duration of the first primary control impulse determines the amplitude of the front edge of the first stage of the boot-type injection rate shape. In the case of a multiple injection, one should select the proper intervals between the control impulses which could assure a boot-type injection rate shape with the desired value of oscillations of the first stage of the boottype fuel injection rate shape.

\section{CONCLUSIONS}

1. Fuel injection causes considerable pressure oscillations at the inlet of the injector. The range of these oscillations depends on injection pressure, control impulse duration, fuel physical properties and the injector design. One of the reasons of the oscillations is the hydraulic impact which takes place when the injector needle valve closes on the seat.

2. Both the pressure drop in the accumulator after the pilot injection (the value of the pressure deviation is $5 \mathrm{MPa}$ depending on the mode) and the voltage drop across the capacitor of the power injector (the current boost of the second injection is by $2.5 \mathrm{~A}$ lower than that of the first one) are responsible for the longer opening of the injectors in the case of the next injection.

3. The presence of the fuel accumulator integrated into the CRI body decreases the wave phenomenon related to the fuel injection process. During recent experiments with the CRI No2 modified with an integrated fuel accumulator $\left(p_{\mathrm{ac}}=1000 \mathrm{bar}, \tau_{\mathrm{imp}}=0.6 \mathrm{~ms}\right.$ ), the impulse amplitude at the inlet to the injector was 120 bar which was for 3.3 times lower than in the case of CRI No1 without the use of fuel accumulator.

4. When fuel accumulator pressure $p_{\text {ac }}$ grows, the oscillation phenomenon and its impact on the working process increase. So, the variation range in the injection rates of the second portion is $Q_{2}=2.36 \ldots 4.62 \mathrm{mg}$, and at $p_{\mathrm{ac}}=3000 \mathrm{bar}, Q_{2}=1.58 \ldots 6.63 \mathrm{mg}$ when operating on diesel fuel at the rail pressure $p_{\mathrm{ac}}=2000 \mathrm{bar}$.

5. After switching the CRI operation to a fuel having higher viscosity, due to the growth of the hydraulic friction, there is a more rapid attenuation of the pressure oscillations caused by the pilot injection. So, when the CRI No1 operates ( $p_{\mathrm{ac}}=1000 \mathrm{bar}, \tau_{\mathrm{imp}}=0.6 \mathrm{~ms}$ ) on sunflower oil, the range of pressure oscillations decreases from $40 \mathrm{MPa}$ (when the diesel engine operates on diesel fuel) to $25 \mathrm{MPa}$ (when the diesel engine operates on sunflower oil).

Acknowledgments: This work was supported by the Russian Science Foundation [grant number 19-19-00598]. Site: https://www.rscf.ru/ 


\section{REFERENCES}

1. Pflaum, S., Wloka, J., Wachtmeister, G., 2010, Emission reduction potential of 3000 bar Common Rail injection and development trends, CIMAC Congress Bergen, Paper No. 195.

2. Shatrov, M.G., Golubkov, L.N., Dunin, A.U., Yakovenko, A.L., Dushkin, P.V., 2015, Influence of high injection pressure on fuel injection perfomances and diesel engine working process, Thermal science, 19(6), pp. 2245-2253.

3. Yu, Y., 2019, Experimental study on effects of ethanol-diesel fuel blended on spray characteristics under ultra-high injection pressure up to $350 \mathrm{MPa}$, Energy, 1861, 115768.

4. Why Higher Injection Pressure Saves Fuel and Also Increases Performance and Torque, 2013, Bosch Media Service.

5. Shatrov, M.G., Malchuk, V.I., Dunin, A.U., Shishlov, I.G., Sinyavski, V.V., 2018, A control method of fuel distribution by combustion chamber zones and its dependence on injection conditions, Thermal Science, 22(5), pp. 1425-1434.

6. Kamaltdinov, V.G., Markov, V.A., Lysov, I.O., Zherdev, A.A., Furman, V.V., 2019, Experimental studies of fuel injection in a diesel engine with an inclined injector, Energies, 12(14), 2643.

7. Iakovenko, A., Dunin, A., Dushkin, P., Savastenko, E., Shatrov, M., 2019, The influence of mass composition of water-fuel emulsion on ecological characteristics of a diesel engine, Energies, 12(14), 2689.

8. Wuethrich, D., Rotz, B., Herrmann, K., Boulouchos, K., 2019, Spray, combustion and soot of water-infuel (n-dodecane) emulsions in a constant volume combustion chamber, Part II: Effects of low temperature conditions and oxygen concentrations, Fuel, 248, pp. 104-116.

9. Wloka, J., Pötsch, C., Wachtmeister, G., 2011, Injection spray visualization for 3000 bar diesel injection, 24th Conference of the Institute for Liquid Atomization and Spray Systems.

10. Grekhov, L., Denisov, A., Starkov, E., 2016, Diesel fuel injection by pressure up to $400 \mathrm{MPa}$, International Journal of Pharmacy and Technology, 8(4), pp. 27208-27215.

11. Zhao, J., Grekhov, L., Yue P., 2020, Limit of fuel injection rate in the Common Rail system under ultrahigh pressures, International Journal of Automotive Technology, 21, pp. 649-656.

12. Vera-Tudela, W., Haefeli, R., Barro, C., Schneider, B., Boulouchos, K., 2020, An experimental study of a very high-pressure diesel injector (up to 5000 bar) by means of optical diagnostics, Fuel, 275, pp. 1-17.

13. Baratta, M., Catania, A., Ferrari, A., 2006, Hydraulic layout effects on multijet C.R. injection system performance and design criteria to remove the pressure wave induced disturbances on sequential injection shots, 61Congresso Nazionale ATI, Perugia, 9 p.

14. Beirer, P., 2007, Experimental and numerical analysis of hydraulic circuit of a high pressure common rail diesel fuel injection system, Tampere: Tampere University of Technology, Finland, 198 p.

15. Catania, A., Ferrari, A., Manno, M., Spessa, E., 2008, Experimental investigation of dynamics effects on multiple-injection common rail system performance, Journal of Engineering for Gas Turbines and Power, ASME, 130(3), 032806.

16. Leonhard, R., Warga, J., Pauer, T., Ruckle, M., Schnell, M., 2010, Solenoid Common Rail injector for 1800 bar, MTZ worldwide, February, pp. 10-15. 